\author{
International Journal of Innovative Research in \\ Electrical, Electronics, Instrumentation and Control Engineering
}

Vol. 9, Issue 10, October 2021

DOI: 10.17148/IJIREEICE.2021.91011

\title{
Experimental Stress Analysis of Prosthetic Knee Joint - A Review
}

\author{
Dr.C. Shashishekar ${ }^{1}$, S. J. Sanjay ${ }^{2}$ \\ ${ }^{1}$ Associate Professor, Department of Mechanical Engineering, Siddaganga Institute of Technology, Tumakuru \\ ${ }^{2}$ Research Scholar, Department of Mechanical Engineering, Siddaganga Institute of Technology, Tumakuru
}

\begin{abstract}
From this paper we came to know that ad its shown us how the work is done on the knee joint to test the joint in the different parameters are taken to know the various differential results and it tells us the importance of the knee joint stress capacity so lets us known that the amount loading conditions are developed in this input parameters. The main work is done based on the dynamic also by the static analysis is done and they are defined separately so that the this paper gives us idea about the knee capacity and stress conditions are to be developed that is also the important thing to know. And discussed about kinematics and that is to be analyzed here for the purpose of the experimentation. This paper concludes that condition of the business with the respect to knee inserts are assessed by mechanical testing techniques.
\end{abstract}

Keywords: Prosthetic knee joint, Experimental Analysis, Mechanical Testing, Load, Femur, Tibia

\section{I.INTRODUCTION}

The introduction of the articular faces of the knee joint are to be arranged on three separate bones the like wise distal completion of the femur bone, the proximal completion of tibia bone, and the back substance of the patella.. The normal and the even condyles are the two different structure of the spheroid structure of the distal completion.. The condyles are to be contact in between the two of the some degree level of the faces on the proximal completion of the parts are like normal and tibia levels. The normal level is essentially round and changing than that of the surface level (1). Various forces working on the knee and pointless pressure on the ligaments by virtue of over load in various activities happen, which impacts the working of knee on account of wounds like break in ligaments (2). The knee prosthetics are the exactly attempted to work out the lifetime of an implant under physiologic stacking conditions and weight bearing cutoff points. Mechanical tests for the torpid clinical devices are routinely surveyed under two guideline orders concerning stacking conditions. These are static and dynamic stacking strategies. Static tests are the one which are concentrated under the semi static stacking condition until the break or yielding occasion. The term semi static means little stacking speeds are that allowed the surface to recover to some degree. Also, dynamic tests are by and huge time subordinate and in this manner the use of upper amounts of cycles occurs. By this sort of tests, weariness or wear execution of the additions are often evaluated. notice that an insert can't be surveyed with static tests figuratively speaking. moreover, to check an insert on extraordinary stacking conditions, static tests are prerequisites (3).

\section{II.KINETICS}

Exact assessment of knee loads during activities of everyday presence has been hard for knee mechanical testing. For the so many last years the standard for knee energy was the ISO standard 14243-1, which tells the stacking conditions at the knee during step. ISO 14243-1 was presented to standardize the stacking conditions used for strength testing of outright knee replacements. The stacking conditions referred to in ISO 14243-1 started from Morrison in the last piece of the 1960s and mid 1970s $(4,5,6)$ through a blend of walk lab optical assessments and mathematical illustrating. During this series of assessments, 14 patients were recorded in the forward looking and sagittal plane while walking around power plate. Estimated ground reaction powers were clubbed with speed increments of the member pieces and a mathematical model of the tibiofemoral contact, ligaments, and mu scles crossing knee. The assessments yielded a mean assumption for knee loads during the step cycle. inside the last piece of the 1990s, Walker and his accomplices were making test procedures to guage the limit and strength of hard and fast knee replacements $(7,8,9)$. Walker et al. have taken the knee stacking conditions during walk portrayed by Morrison into stacking profiles for a four-station knee wear test framework. since the strong business became through the 2000s, the stacking used by Walker et al. were standardized by the world relationship for Standards, for certain slight changes in accordance with the front back and compressive weights, into ISO 14243-1. inside the last piece of the 1990s and 2000s, three investigation packs made and installed 


\section{International Journal of Innovative Research in \\ Electrical, Electronics, Instrumentation and Control Engineering}

Vol. 9, Issue 10, October 2021

\section{DOI: $10.17148 /$ IJIREEICE.2021.91011}

telemetered full scale knee replacement parts. Taylor and Walker are an instrumented distal femoral part into two patients that are supposed to be could have measure critical loads and bending of the minutes $(10,11)$. There are the Ortho stacking of that pack at Charit drove by Bergmann installed a movement of instrumented tibial plate that activity six degrees of chance stacking into nine outright knee replacement patients(12,13). Using these are some of the telemetered supplements, knee forces and minutes were depicted for a fair sort of activities of step by step living and are made straightforwardly available through the Orth load site. Near a similar time, D'Lima and accomplices implanted a substitute sort of instrumented tibial plate into different patie nts to in like manner check in vivo loads $(14,15,16,17)$.
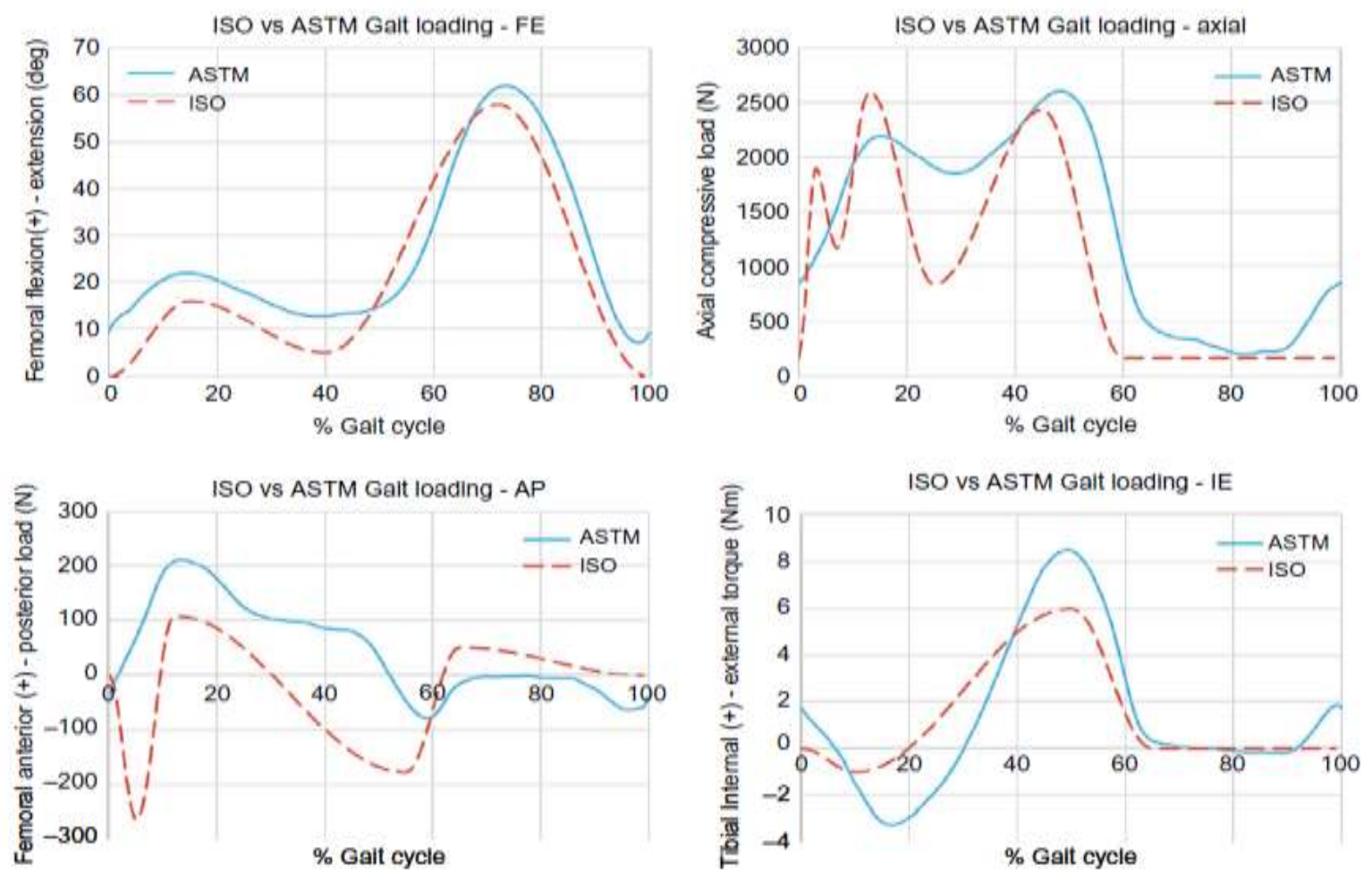

Fig 2.1 A graphical correlation of the knee stacking conditions during stride as endorsed by ISO 1243 (red) and by ASTM F3141 (blue). The ISO standard depended on movement catch examinations acted in the last part of the 1960s while the ASTM standard depended on estimations from in vivo instrumented tibial plate embedded during the 2000s.

The openness of in vivo joint stacking data for hard and fast knee replacements clarified the stacking conditions at the knee that had as of late been theoretically expected using development get data and force plates. The typical of the patients with the Ortho load implant performing step, step rising and pleasant, sit-to-stand, and transforming not set in stone and made into ASTM standard F3141. An assessment of the ISO and ASTM step stacking standards shows brilliant likenesses given the radically different techniques and time periods with which the two educational lists were accumulated. While the stacking assessed in vivo are the best data available, it is bound in that it offers data to few patients, during confined activities, and with only three plans of hard and fast knee replacements. Considering these information we comprehend that colossal patient-to-patient assortment and intrapatient assortment (i.e., dare to-step assortment) exists in the stacking conditions. Musculoskeletal showing offers an elective methodology to expect knee powers using refined systems that cutting-edge from the first stacking expected by Morrison $(4,5,6)$. Musculoskeletal showing relies upon development get data to depict the patients' advancements joined with power plates to depict the ground reaction forces and EMG to depict muscle activation plans. Utilizing mathematical models and smoothing out estimations, investigators would it be able to foresee knee stacking (18). Lately, step data and tibial weights from D'Lima's instrumented tibial plate were made available and experts were drawn nearer to survey the insightful show of their mathematical models. In general the mathematical model assumptions show an incredibly stunning simultaneousness with the purposeful tibial weights, advancing sureness to the farsighted limit of the technique and possibly enlarging the openness of knee stacking data for extra patients, works out, and install types (19) 


\section{International Journal of Innovative Research in \\ Electrical, Electronics, Instrumentation and Control Engineering}

Vol. 9, Issue 10, October 2021

\section{DOI: 10.17148/IJIREEICE.2021.91011}

\section{EXPERIMENTAL STUDY}

3.1 Compressive Test of Tibia bone arrangements with investigation of Tibia bone obstruction in three upper, center and terminal parts as exploratory through compressive test and limited component strategy directed by FarshadVatankhahan and Moeinoddin (20). After compressive test on three regions, as per the aftereffect of stress-strain graph,it showed that Tibia bone has the most strength in the center region however it has the less strength in the upper region.

3.2 On Thickeness by Ali M. Alsamhant substitution evaluation manages one of as far as possible in controlling the fate of the phony knee, which is the thickness of the polyethylene layer of Tibia Tray of fake knee joint. Three obvious thickness of polyethylene layers $(8,9$, and $10 \mathrm{~mm})$ which are accessible at emergency focuses accumulated with comparative hazy tibia plate. This made specialists confounded in regards to which polyethylene layer thickness to pick. It was tracked down that the strength of polyethylene and the strength of significant constituents of the fake knee are stretched out with polyethylene layer thickness (21).

3.3 Vivo Kinematics In vivo kinematics of the tibio femoral joint was gotten from open MRI for 12 sound subjects for knee flexion under both dormant and dynamic neuromuscular models. A typical tibial internal turn of $1.8^{\circ}{ }_{-} 0.9^{\circ}$ was seen for the unloaded knee at $30^{\circ}$ and $7.1^{\circ} \_4.6^{\circ}$ at $90^{\circ}$ knee flexion, while an ordinary tibial internal upset of $4.0^{\circ} \_2.5^{\circ}$ occurred at $30^{\circ}$ and $5.6^{\circ} \_3.6^{\circ}$ at $90^{\circ}$ for the stacked knee concentrated by Heller M O, König C, Graichen H, etal (22) . 3.4 Force and Moment Calculation Strain check transducers were used for the assessment of ability to process minutes, by which knee point of convergence of turn was evaluated by Riener R, Quintern J, Schmidt G (23). The subsequent exercises were sent by the progression of strain in solid or ligamentous affiliations crossing the joint and the looking at reaction at the joint.

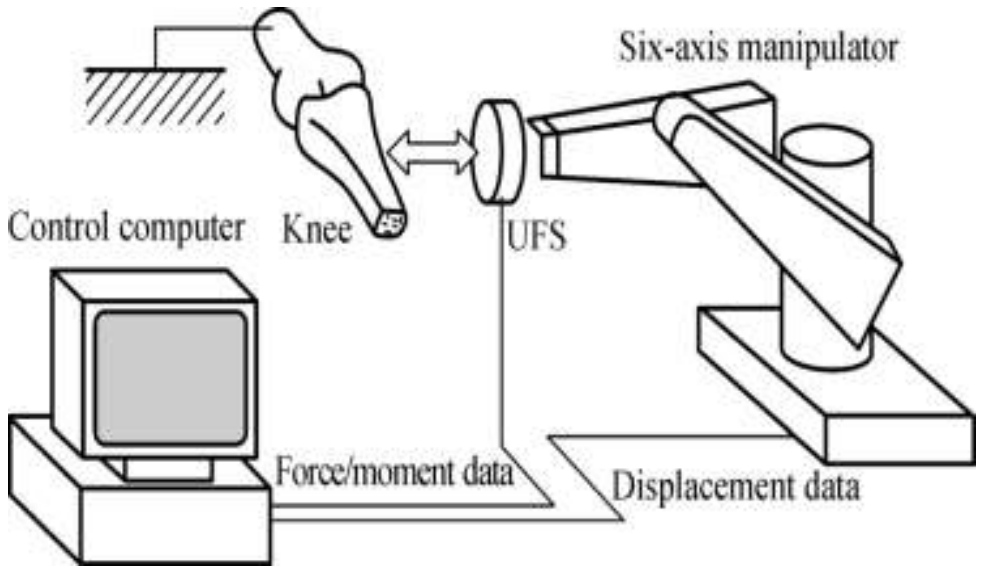

Fig 3.4.1 Robotic system to control forces and moments at the human knee joint

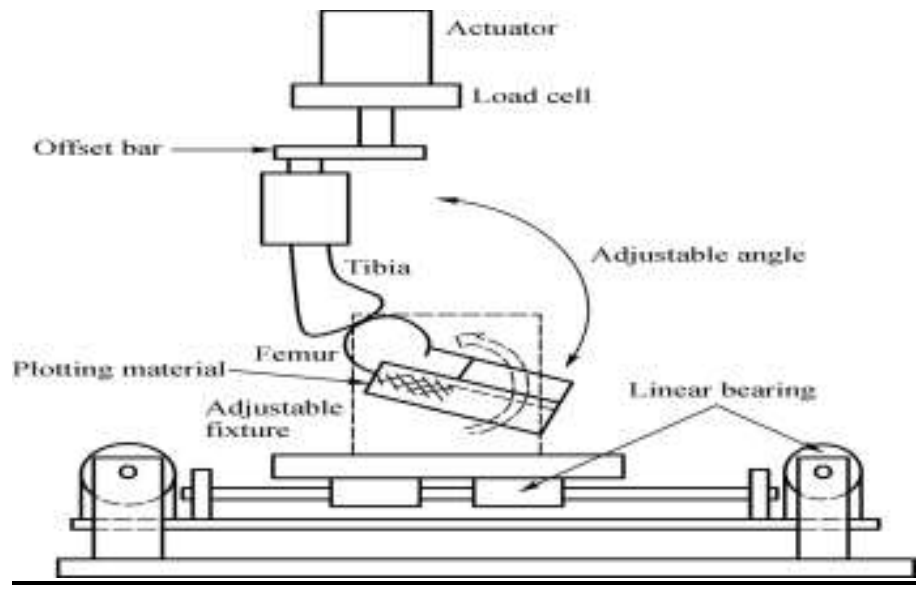

Fig 3.4.2 Tibia and femur joint loading arrangement

3.5 Assessment of the Errors Kaufman K R, A K Y, Chao Y (24) in their study Quantification of the goofs related with assessments was gotten using an isokinetic dynamometer for knee evaluation at $60^{\circ} / \mathrm{s}$ to $180^{\circ} / \mathrm{s}$. Five customary subjects were attempted. A triaxial electrogoniometer was used for assessing the kinematics. An exceptionally created load cell was used to count the three even pieces of the reaction power applied by the isokinetic dynamometer to the leg. 


\section{International Journal of Innovative Research in \\ Electrical, Electronics, Instrumentation and Control Engineering}

Vol. 9, Issue 10, October 2021

\section{DOI: $10.17148 /$ IJIREEICE.2021.91011}

3.6 Power Velocity Relationship The dynamometer with the high time-objective servo system has been actually made to assess the isotonic force speed associations. This servo system can evaluate power under the reliable state and gives one more estimation to appreciate power speed characteristics of human multi-joint turns of events. The force speed associations were immediate in both corresponding and uneven knee-hip extension improvements and in both young and old women so most noteworthy isometric force, Fmax, and unloaded speed,Vmax, could be assessed by extrapolating the straight relapses on to the power separately clarified by Yamauchi J and Ishii N(25).

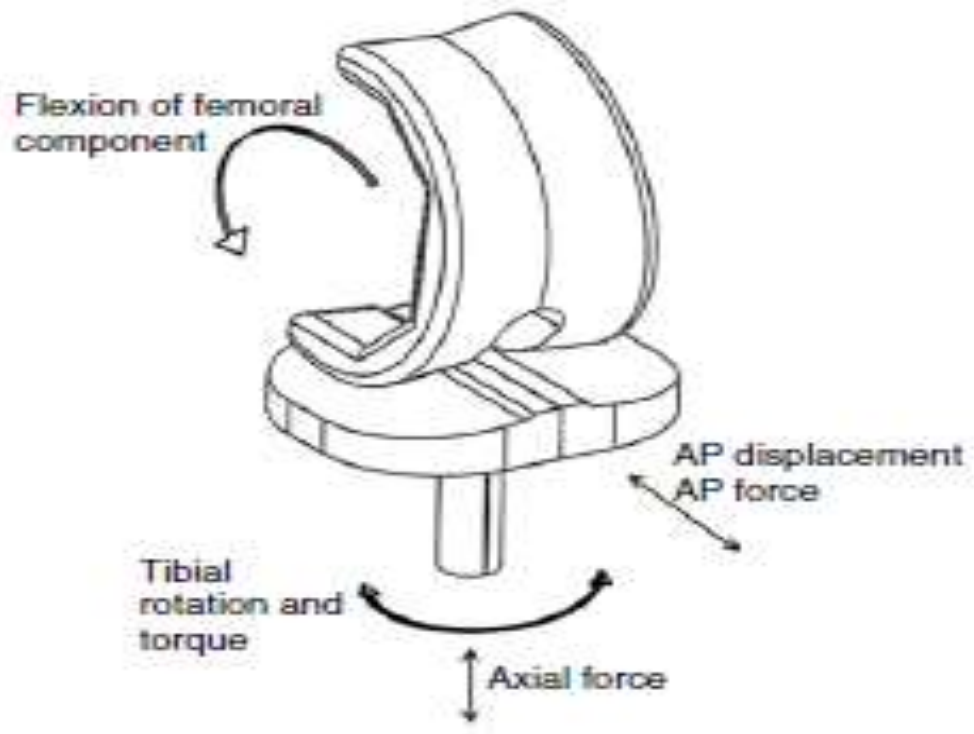

Fig 3.6 Forces, torques, and motions of a total knee joint prosthesis

3.7 Quadriceps Force The quadriceps muscles of human body are exceptionally huge in consistently activities of knee joints. The confirmation of quadriceps powers presents basic troubles since it can't be assessed in vivo. A unique approach was presented by Guo Y, Zhang X S, A M W, et al (26)to procure the forces in squat through the mix of development photography, power transducers measures, multi-rigid body theory and restricted part assessment methodology.

3.8 Knee Interactive Forces Various systems like decline, improvement, telemetry for relationship of knee affiliation powers for different activities like walking, step plunge, step climb, etc, for these entire activities knee astute forces still up in the air. In walking it is around 2 - on various occasions the body weight, in sync climbing it is about $2.8-4.4$ events the body weight, in sync drop it is about $2.8-4.9$ events the body weight. These forces are made on knee in various activities and given concerning the body loads inspected by Komistek R D, Kane T R, Mahfouz M, et al.(27) Moments made on the knee are similarly procured by everyday presence works out.

\section{MECHANICAL TESTING}

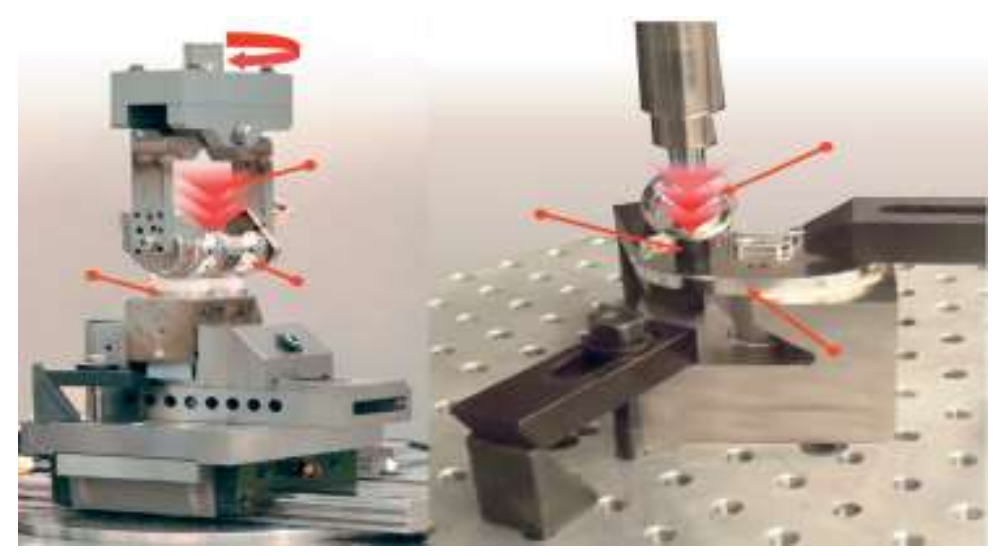

Fig 4.1 Mechanical test set-ups to assess a complete knee develop I-E limitation under ASTM standard F1223 (left) and a tibial base exhaustion portrayal under ASTM standard F1800 (right). 


\section{International Journal of Innovative Research in Electrical, Electronics, Instrumentation and Control Engineering \\ Vol. 9, Issue 10, October 2021}

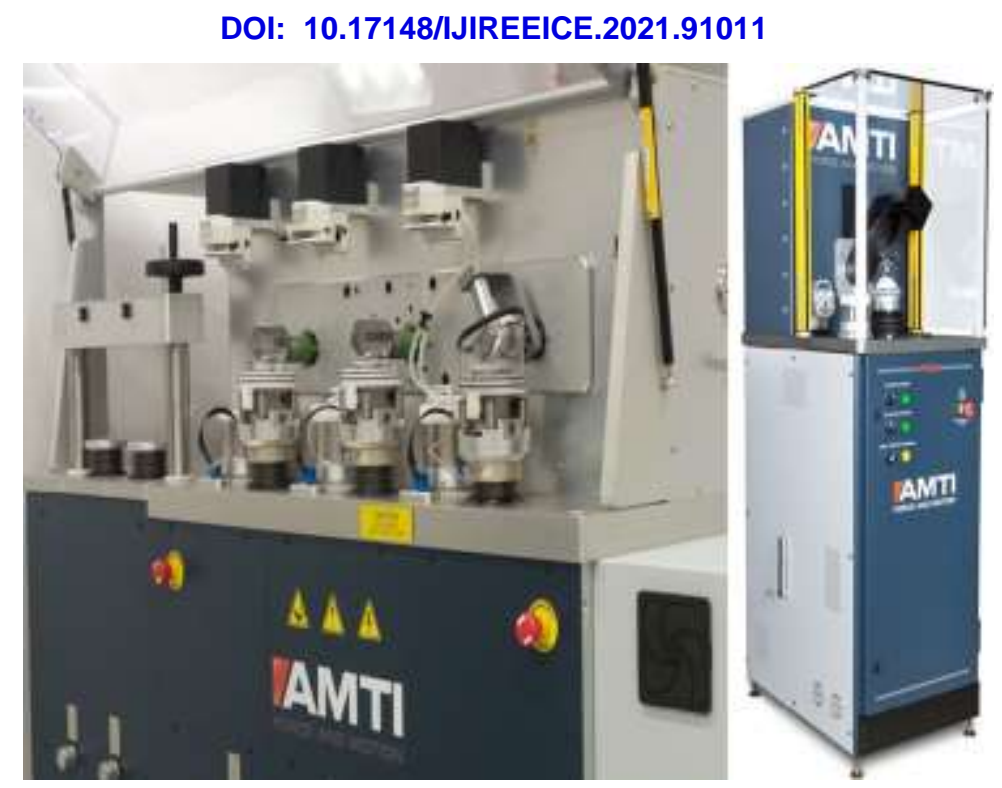

Fig 4.2 The AMTI wear test system has been the business standard for estimating knee wear (left). All the more as of late, progressed wear test systems like the AMTI VIVO give expanded stacking adaptability to evaluate more modern stacking conditions.

Exhaustion testing of the metallic tibial plate part is performed by ASTM F1800 (28). The methodology gauges the shortcoming execution of the metallic tibial plate part of the knee joint prosthesis. The wear testing of the outright knee joint prosthesis is performed by ISO 14243. The technique shows the by and large saucy advancement between articulating parts and the case of the applied force.
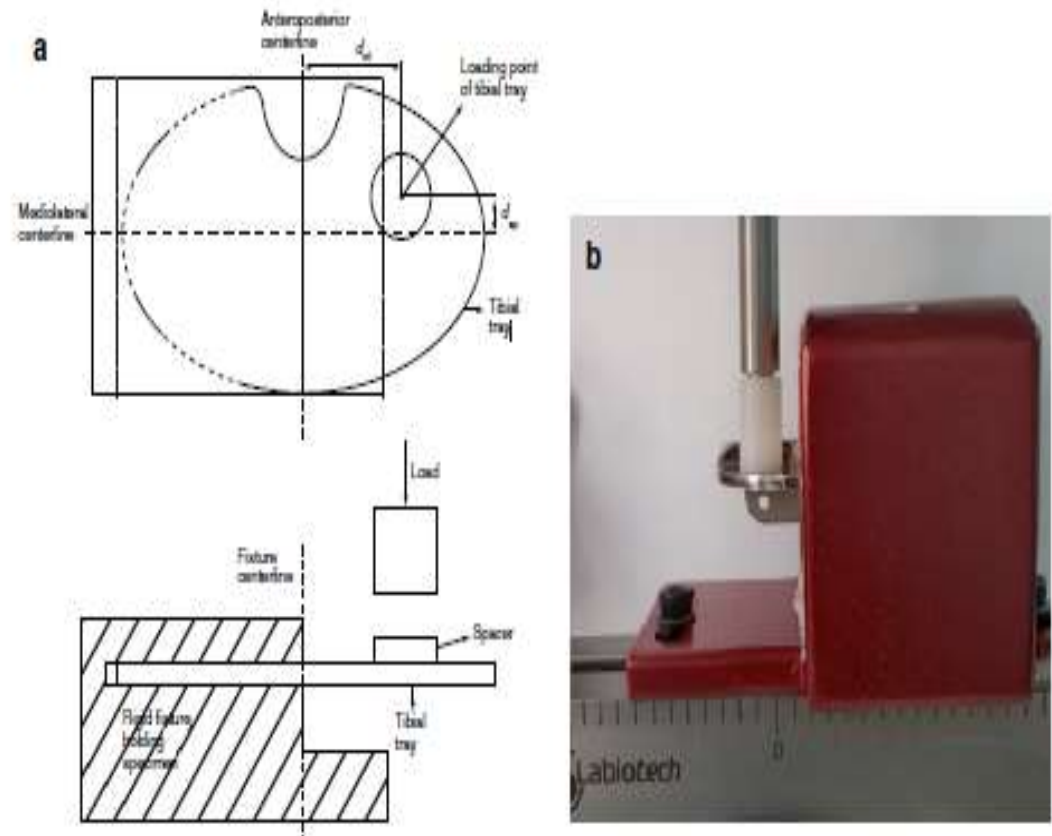

Fig 4.3 The weariness test arrangement for the tibial plate parts. (a) Schematic view, (b) see got from test

\subsection{Interpretation of Results}

For the approach for fatigue test suggested degree $\mathrm{R}$ is 10.0. The test continues until the tibial plate breaks or a most incredible number of cycles is reached. For the fatigue testing of tibial plate, the most ridiculous number of cycles is $10,000,000$ cycles. While for weartest,the test proceeds until 5,000,000 cycles or a partition of the articulating surfaces. 


\title{
International Journal of Innovative Research in \\ Electrical, Electronics, Instrumentation and Control Engineering
}

\author{
Vol. 9, Issue 10, October 2021
}

\section{DOI: 10.17148/IJIREEICE.2021.91011}

\section{CONCLUSION}

The appraisal of knee embeds has continued to create since outright knee replacement became ordinary spot during the 1970s. Countless the ordinary disillusionment techniques for prosthetic knee joint have been completely investigated and directed in current plans. In any case, not in the least like hard and fast hip replacement patients, an enormous degree of outright knee patients stay frustrated with their outcome showing that further created plans and cautious systems are required (29). As subject matter experts and draftsmen continue to innovative new plans, further created testing procedures ought to be made to isolate between these plans and assurance their security and adequacy. The latest several years have seen a quick speed expansion in understanding the mechanics of the inserted knee joints. With the extended openness of stacking data from machined supplements of authentic patients to the exciting redesigns in the farsighted power of musculoskeletal models, the down to earth demands set on knee implant parts are ending up being obvious. Similarly, the fast improvement of imaging modalities like enrolled tomography sift suggests we find through with regards to the vacillation in lower member life structures across different patient masses. The mix of a predominant data on knee stacking, better anatomic data, and astonishing judicious models will unquestionably incite the introduction of standard knee embeds revamp for individual patients that further foster execution (30).

\section{REFERENCES}

1. Martelli, S., Pinskerova, V, "The shapes of the tibial and femoral articular surfaces in relation to tibiofemoral movement", The Journal of bone and joint surgery. British, 2002, Volume : 84, Issue:(4), PP:607-13, doi: 10.1302/0301-620x.84b4.12149.

2. Savio L-Y Woo, Steven D Abramowitch, Robert Kilger, Rui Liang, "Biomechanics of knee ligaments: injury, healing, and repair", Journal of Biomechanics, 2006; Volume : 39, Issue: (1), PP :1-20, doi: 10.1016/j.jbiomech.2004.10.025.

3. Robert Wendlandt, Christian Jürgens, Arndt P. Schulz, "Bone plate-screw constructs for osteosynthesis - Recommendations for standardized mechanical torsion and bending tests", Journal Biomedical Engineering, 2017,Volume : 63, Issue: (6),DOI:10.1515/bmt-2017-0126.

4. I J Harrington, "A Bioengineering analysis of force actions at the knee in normal and pathological gait", Journal of Biomechanics, 1976 ; Volume :11, Issue: (5),PP:167-72.

5. J B Morrison, "Function of the knee joint in various activities", Biomedical Engineering, 1970,Volume : 4 , Issue: (12),PP: 573-580.

6. Morrison, J.B, “ The mechanics of the knee joint in relation to normal walking", Journal of Biomechanics, 1970, Volume : 3, Issue: (1),PP: 51-61. PubMed: 5521530.

7. P S Walker, H H Hsieh. "Conformity in condylar replacement knee prostheses", The Journal of bone and joint surgery, 1977 , Volume : 59, Issue: (2),PP:222-228, doi: 10.1302/0301-620X.59B2.873983

8. $\quad$ Walker, P.S., Blunn, G.W., Broome, D.R., Perry, J., "Watkins, A., Sathasivam, S., Dewar, M.E., Paul, J.P., “A knee simulating machine for performance evaluation of total knee replacements. Journal of Biomechanics, 1997, Volume: 30, Issue: (1),PP: 83-89.

9. Walker, P.S, Blunn, G.W, Perry, J.P., Bell, C.J, Sathasivam, S, Andriacchi, T.P, Paul, J.P, Haider, H, Campbell, P.A, "Methodology for long-term wear testing of total knee replacements", Clinical Orthopaedics and Related Research, 2000, Volume:372, PP:290-301. PubMed: 10738439.

10. Taylor, S.J., Walker, P.S., "Forces and moments telemetered from two distal femoral replacements during various activities". Journal of Biomechanics, 2001. Volume: 34, Issue: (7), PP:839-848.

11. Taylor, S.J., Walker, P.S., Perry, J.S., Cannon, S.R., Woledge, R, "The forces in the distal femur and the knee during walking and other activities measured by telemetry", Journal of Arthroplasty,1998, Volume:13, Issue: (4),PP: 428-437.

12. Heinlein, B., Graichen, F., Bender, A., Rohlmann, A., Bergmann, G., "Design, calibration and pre-clinical testing of an instrumented tibial tray" Journal of .Biomechanics. 2007, Volume:40, Issue: (Suppl. 1), PP:S4-S10.

13. Heinlein, B., Kutzner, I., Graichen, F., Bender, A., Rohlmann, A., Halder, A.M., Beier, A., “ Bergmann Clinical Biomechanics Award complete data of total knee replacement loading for level walking and stair climbing measured in vivo with a follow-up of 6-10 months", Clinical biomechanics. 2008: Volume:24, Issue: (4), PP:315-326.

14. $\quad$ D.Lima, D.D., Patil, S., Steklov, N., Slamin, J.E., Colwell Jr., C.W., “ The Chitranjan Ranawat Award: in vivo knee forces after total knee arthroplasty. Clinical Orthopaedics and Related Research ,2005, Volume:440, PP:45-49.

15. D’Lima, D.D., Patil, S., Steklov, N., Slamin, J.E., Colwell Jr., C.W, “ Tibial forces measured in vivo after total knee arthroplasty”, “Journal of Arthroplasty" 2006, Volume:21, Issue: (2), PP:255-262.

16. D’Lima, D.D., Patil, S., Steklov, N., Chien, S., Colwell, C.W., "In vivo knee moments and shear after total knee arthroplasty", Journal of Biomechanics. 2007, Volume:40, PP:S11-S17.

17. D’Lima, D.D., Steklov, N., Patil, S., Colwell Jr., C.W., "The Mark Coventry Award: in vivo knee forces during recreation and exercise after knee arthroplasty", Clinical Orthopaedics and Related Research., 2008, Volume:466, Issue: (11), PP:2605-2611.

18. Shelburne, K.B., Pandy, M.G., , "A musculoskeletal model of the knee for evaluating ligament forces during isometric contractions. Journal of Biomechanics.,1997, Volume:30, Issue: (2),PP: 163-176.

19. Kinney, A.L., Besier, T.F., D’Lima, D.D., Fregly, B.J., “ Update on grand challenge competition to predict in vivo knee loads.” Journal of Biomechanics, 2013. Volume:135, Issue: (2),PP: 021-012. http://dx.doi.org/ 10.1115/1.4023255.

20. Farshad Vatankhahan ,Moeinoddin, "Resistance analysis of Tibia bone on upper, midella and terminal sections by compressive strength testing and FEM". Journal of Biomechanics ,2016 Volume: 2:PP: 345.

21. Ali M.Alsamhan, "Rationale analysis of human artificial knee replacements", Journal of King Saud University - Engineering Sciences, 2013,

Volume: 25, Issue: 1, PP: 49-54.

22. Heller M O, König C, Graichen H, "A new model to predict in vivo human knee kinematics under physiological-like muscle activation". Journal of Biomechanics, 2007, Volume: 40, Issue: (Suppl 1), PP:S45-S53.

23. Riener R, Quintern J, Schmidt G. "Biomechanical model of the human knee evaluated by neuromuscular stimulation". Journal of Biomechanics, 1996, Volume:29, Issue: (9), PP:1157-1167.

24. Kaufman K R, An K Y, Chao E Y. "A comparison of intersegmental joint dynamics to isokinetic dynamometer measurements". Journal of Biomechanics, 1995, Volume: 28, Issue: (10),PP: 1243-1256. 


\section{International Journal of Innovative Research in Electrical, Electronics, Instrumentation and Control Engineering}

Vol. 9, Issue 10, October 2021

\section{DOI: 10.17148/IJIREEICE.2021.91011}

25. Yamauchi J, Ishii N. "Relations between force-velocity characteristics of the knee-hip extension movement and vertical jump performance". Journal of Strength and Conditioning Research/ National Strength \& Conditioning Association, 2007, Volume: 21, Issue: (3),PP:703-709.

26. Guo Y, Zhang X S, An M W, "Determination of quadriceps forces in squat and its application in contact pressure analysis of knee joint". Acta Mechanica Solida Sinica, 2012, Volume:25, Issue: (1),PP:53-60.

27. Komistek R D, Kane T R, Mahfouz M, "Knee mechanics: A review of past and present techniques to determine in vivo loads". Journal of Biomechanics, 2005, Volume:38, Issue: (2),PP: 215-228.

28. ASTM F1800-12 "Standard practice for cyclic fatigue testing of metal tibial tray components of total knee joint replacements". ASTM International, West Conshohocken. (2012).

29. Bourne, R.B., Chesworth, B.M., Davis, A.M., Mahomed, N.N., Charron, K.D., 2010. "Patient satisfaction after total knee arthroplasty: who is satisfied and who is not? ",Clinical Orthopaedics and Related Research. Volume:468, Issue: (1), 57-63. http://dx.doi.org/10.1007/s11999-009-11199.

30. C. Clary, L. Maletsky, "Mechanical testing of knee implants", Journal of Orthopedic Implants. 2013, DOI:10.1016/B978-0-08-1002865.00011-1Corpus ID: 79682800 